\title{
Institutional Investor Information Sharing, Stock Market Extreme Risk, and Financial Systemic Risk
}

\author{
Xiao-Li Gong $(\mathbb{D})$ and Zhi-Qiang Du \\ School of Economics, Qingdao University, Qingdao, 266061, China \\ Correspondence should be addressed to Xiao-Li Gong; qdgongxiaoli@126.com
}

Received 3 December 2019; Revised 15 February 2020; Accepted 17 March 2020; Published 9 April 2020

Academic Editor: Dehua Shen

Copyright (c) 2020 Xiao-Li Gong and Zhi-Qiang Du. This is an open access article distributed under the Creative Commons Attribution License, which permits unrestricted use, distribution, and reproduction in any medium, provided the original work is properly cited.

\begin{abstract}
To analyze whether information sharing in the institutional investors plays the role of a market stabilizer or risk booster, this paper constructs the institutional investor information network employing the common holding stocks of the mutual funds as links. The information linkages between two funds with large positions in the same stock are hypothesized to be connected to each other. Then, we use the information sharing efficiency in the fund networks to study the effects of information transmission on stock market extreme risk and financial systemic risk. Especially, the speed of information diffusion in the network is characterized by the topology structures based on social network theory. Empirical research studies find that the Chinese fund information network exhibits small-world characteristics, which reflects rapid speed of information diffusion. Seen from the idiosyncratic risk of volatility, information sharing of institutional investors can improve the behavior consistency of fund managers, thus increasing the stock volatility via herd effects. Besides, it can be concluded that institutional investor information sharing can reduce the extreme risk by promoting the comprehensiveness of information flow and the market pricing efficiency of stocks, thereby reducing the degree of financial systemic risk. The obtained conclusions provide suggestions for decision-making of institutional investors. It can help the regulators to pay attention to the herd effects so as to control systemic risk.
\end{abstract}

\section{Introduction}

In recent years, the China Securities Regulatory Commission vigorously develops institutional investors. This strategy changes the situation in the Chinese capital market which is dominated by retail investors. In 2019, retail investors accounted for $31.4 \%$ of the market capitalization, and institutional investors accounted for $53.2 \%$ of the market capitalization. In the Chinese financial market, institutional investors are mainly based on securities investment funds. Due to its professional team and information advantages, institutional investors can easily trigger the herd effects of trading behavior through mutual learning and imitation in the same social ties [1]. Along with the booming development of institutional investors, China's stock market has become increasingly volatile. Also, the extreme risks of stock market occur more frequently. In addition to the subprime mortgage crisis in 2008, thousands of stocks fell in June 2015 due to the stock market crash in China. Hence, it led to the discussion that whether institutional investors play the role of amplifying market volatility due to herding behaviors [2], or stabilize the market with professional research teams [3].

Since the linkage between institutional investors has been strengthened, it means that there exists endogenous risk contagion in the stock markets. Therefore, it is meaningful to study the impact of information diffusion of institutional investor networks on stock market extreme risk and financial systemic risk. It can provide references for regulators to maintain financial stability and prevent financial crises caused by systemic risk contagion.

Investors often actively seek private information through social relationships when making decisions [4-6]. Fund managers in the same information network tend to display more obvious herd effects [7]. Information exchanges among investors can affect the stock price volatility [8-10]. In order to analyze the influence mechanism of institutional 
investors on the financial risks, it is necessary to analyze the information dissemination features of this community. In recent years, financial networks have become an efficient tool in studying financial risk transmission as well as information dissemination $[11,12]$. Networks play a vital role in the information flow through financial markets. Colla and Mele [13] found that closely related investor behaviors in the information networks are more likely to produce herd effects. Sharing private information among fund managers is the rational choice for maximizing their own interests [14]. Moreover, the topological structure characteristics of the social networks among fund managers can affect the effectiveness of information exchange and risk contagion [15]. According to Pareek [7], an information or stock ownership linkage between two mutual funds is defined by large positions in the same stock. The stock information network corresponds to the fund manager set amongst whom information concerning stock diffuses via word of mouth or via common sources of private information. Hence, this paper assumes that there exists private information exchange between the funds that have common holdings of stocks. Besides, previous studies have found that the formation of information networks is mainly based on social relationships and asset allocation [16]. Then, the institutional investor network can be constructed using the common holding stocks of the mutual funds as links. Further, we can analyze the impacts of information sharing efficiency in the network on stock price volatility and systemic risks.

Stock volatility cannot be directly observed, which needs to be extracted from the returns. The risk driven by the common components of economic fundamentals cannot be dispersed, while the idiosyncratic risk of individual stocks can be managed. Although the beta risk in the CAPM model or the Fama-French three-factor model can calculate the individual stock volatility, it does not examine the extracted idiosyncratic risk from the stock market when faced with common shocks. Especially, when calculating idiosyncratic risks, high-dimensional time series are prone to the "curse of dimensionality" problem. To tackle this problem, Barigozzi and Hallin [17] extended the generalized dynamic factor model (GDFM) based on Forni et al. [18] to decompose the stock volatility into the common shock-driven components and the idiosyncratic components. Then, it extracts the market volatility shock to investigate the volatility spillover effects. The advantage of GDFM is that it can achieve dimensionality reduction for high-dimensional data in the stock market without losing information. Therefore, we continue to employ this method for calculating idiosyncratic stock volatility.

Financial systemic risk denotes the risk that causes financial system damage and the financial service interruption, which will seriously harm the real economy. Adrian and Brunnermeier [19] proposed the notion of the conditional value at risk (CoVaR) based on $\mathrm{VaR}$, which refers to the risk value of other institutions or the entire financial system when the particular institution is in a certain state. Rodríguez-Moreno and Peña [20] pointed out that $\Delta \mathrm{CoVaR}$ can well capture the tail risk in extreme cases. Acharya et al. [21] proposed the concept of marginal expected loss (MES) based on ES, which represents the expected loss of single institution's returns when the entire financial market falls. Using CoVaR and MES to measure systemic risk has become the mainstream method for the current risk management, such as Karimalis and Nomikos [22]. The commonly used calculation methods for $\mathrm{CoVaR}$ include the quantile regression method, the GARCH-DCC model method, and the Copula method. As we all know, the volatility of financial returns shows stochastic volatility features. Hence, it is necessary to consider the clustering characteristic of financial returns when using financial data. Therefore, this paper utilizes the AR-GARCH-DCC-based method to calculate CoVaR and MES when calculating systemic risk.

At present, research studies on institutional investors mainly focus on the governance role $[23,24]$, paying less attention to their market behaviors. There are not yet researches on the relationship between information sharing efficiency and financial systemic risk from the perspective of institutional investor information networks. In this paper, we hypothesize that two fund managers allocating $5 \%$ or more of portfolio to the same stock are connected to each other. And, information about the same stock is likely to diffuse through common information sources. Then, it is significant to investigate the effect of information sharing in the institutional investor network on the financial risk in the stock market.

The innovative contributions of this study over the existing literature mainly include the following aspects. Primarily, the information network of institutional investors is constructed using the common holding stocks of fund as links. Specifically, we define the fund information network as all other funds which hold more than $5 \%$ of portfolio in any stock in which the fund has also invested at least $5 \%$ of its portfolio. The information linkages between two funds with large positions in the same stock are hypothesized to be connected to each other. Then, the network information diffusion features are characterized by the network topology structures. On this basis, we further analyze the relationship between the structure characteristics of the fund network and different financial risks (including idiosyncratic risk, extreme risk, and systemic risk). Secondly, concerning the volatility of individual stocks, the GDFM model is used to extract idiosyncratic volatility from high-dimensional data considering that the stock market will be affected by the common information flow. Thirdly, when calculating the financial systemic risk, the corresponding systemic risks are computed taking into account the clustering and stochastic volatility features of the stock data.

\section{Model Framework}

In this paper, we mainly focus on the trading behavior of transactional institutional investors, which are represented by the mutual equity investment funds. Institutional investors can directly exchange information and correct their cognitive bias through indirect social learning. The institutional investor network has an important impact on stock price volatility and stock market extreme risk, which further affects financial systemic risks. The extent of information 
dissemination in the institutional investor network is related to the efficiency of information sharing. This paper employs the topological indicators reflecting the structure of the fund information network as the proxy variables of institutional investor information sharing efficiency. Specifically, the network centrality and network density indicators are mainly used to measure the efficiency of information sharing. Concerning the different sources of risks, it is divided into three levels, namely, the idiosyncratic risk of individual stocks, the extreme risk of the stock market, and the financial systemic risk.

\subsection{Institutional Investor Information Network. In the in-} stitutional investor information network, if two funds hold common stocks with large position, then the two funds are defined to be in the same fund information network. The fund holding stocks with large position mean that the market value of the fund that hold the stock accounts for more than $5 \%$ of the total market capitalization of the shareholdings. Institutional investors need to rely on public information and private information in their decisionmaking processes. Public information refers to information obtained from the open market, such as historical transaction information, financial statement information, and the behavior of other investors. Private information mainly refers to the information disseminated by investors within a small scope and the unique information existing in the social relationships in which they are located. Due to the information sharing of private information, the herd effects of fund managers in the same information network are usually more obvious. Therefore, private information plays a vital role in the decision-making of institutional investors.

The information advantage of institutional investors' decision-making and trading behavior often comes from private information. Direct information exchange between institutional investors through social relations can verify the information they have. And through indirect social learning, they can correct their own cognitive biases. In the same information network, the sharing of private information improves the consistency of trading strategies, and the produced pseudoherding effects further affect the stock price volatility and financial risks. The fund information network is the collection of all other funds that are in the same information network. This paper uses the data of China's mutual funds to construct the institutional investor network model linked by the fund's common holding stocks. If institutional investors learn from each other through information networks, the structure of networks can help understand the process of information flow. The institutional investor network topology is utilized to characterize the information sharing efficiency, as well as the influence mechanism of institutional investor information sharing on the stock market extreme risk and financial systemic risk. Specifically, the information sharing efficiency of the investor network is characterized by the indicators including the degree of network centralization and the network density.
The degree of the centralization of the graph in the institutional investor network portrays the overall centrality of the network graph. It indicates how much the institutional investor network is constructed around certain special nodes, which can be calculated as follows:

$$
\begin{aligned}
& \text { degree }=\sum_{k-1}^{N} \frac{\left(D\left(n_{\max }\right)-D\left(n_{k}\right)\right)}{(N-2)}, \\
& D\left(n_{k}\right)=\frac{d\left(n_{k}\right)}{(N-1)},
\end{aligned}
$$

where $d\left(n_{k}\right)$ represents the degree of node $n_{k}$ in the network and $D\left(n_{\max }\right)$ represents the maximum value of $D\left(n_{k}\right)$. The larger degree value means that there exist nodes that play critical roles in the propagation of network information, and these key nodes affect the speed of information diffusion in the network, accelerating the information spreading.

The network density in the institutional investor network denotes the ratio of the number of the actual edges $E_{i}$ among the $k_{i}$ neighbor nodes of node $v_{i}$ and the total number of possible edges $M_{k_{i}}^{2}$, which is shown in formula (2). The network density of the node represents the closeness of the relationship between the node and its neighboring. The greater the network density of the node, the more obvious the clustering phenomenon in the network, which will hinder the comprehensive dissemination of information:

$$
\text { density }=\frac{E_{i}}{M_{k_{i}}^{2}},
$$

in which the greater the value of the network density, the more "small groups" that are closely connected in the network. Such small groups often generate hindrance to the information transmission within the network for the sake of profit. Therefore, network density reflects the information transmission degree within the network.

Because of the strong social ties and effective information transmission channels between fund managers, the network formed by the interaction of institutional investors will produce herd effects within the community, which easily lead to extreme risks in the market. Furthermore, the financial systemic risk contagion can be analyzed by means of the network structure characteristics of information sharing among institutional investors.

\subsection{Stock Market Extreme Risk and Financial Systemic Risk}

2.2.1. Idiosyncratic Risk. Regarding the volatility of individual stocks, traditional methods such as the standard deviation, the GARCH model, and the CAPM model did not reasonably reflect the overall idiosyncratic risk of the stock market. However, the nonparametric generalized dynamic factor model can decompose the volatility sequence into the common factor-driven volatility component and the idiosyncratic volatility component.

When using high-dimensional data to calculate the idiosyncratic volatility risk in the stock market as a whole, it will face the "dimensional curse" problem. 
Fan et al. [25] decomposed the covariance matrix of highdimensional financial data into the sum of "low rank plus sparse" type, corresponding to the common components and the idiosyncratic components, respectively. Barigozzi and Hallin [17] proposed the two-stage GDFM method to decompose the overall volatility vector $\mathbf{Z}_{n}$ into the common volatility component and the idiosyncratic volatility component as shown in formula (3). Then, the idiosyncratic volatility of the stock market is extracted, and the decomposition of components is mainly based on the dynamic principal component concept of Brillinger:

$$
\begin{aligned}
& \mathbf{Z}_{n, t}=\mathbf{X}_{n, t}+\mathbf{Y}_{n, t}=\mathbf{B}_{n}(L) \mathbf{u}_{t}+\mathbf{Y}_{n, t}, \\
& \left(\mathbf{I}_{n}-\mathbf{C}_{n}(L)\right) \mathbf{Z}_{n, t}=\mathbf{H}_{n} \mathbf{u}_{t}+\left(\mathbf{I}_{n}-\mathbf{C}_{n}(L)\right) \mathbf{Y}_{n, t},
\end{aligned}
$$

in which $L$ represents the lag operator of the filter $\mathbf{B}_{n}$, the impact vector $\mathbf{u}_{t}$ represents the orthogonal white noise process, which is orthogonal to $\mathbf{Y}_{n, t}$ and can be loaded by the matrix load $\mathbf{H}_{n}, \mathbf{C}_{n}(L)$ denotes the block diagonal matrix of the filter, so that the VAR operator $\mathbf{I}_{n}-\mathbf{C}_{n}(L)$ has no characteristic roots in the unit circle and is square-addable, $\mathbf{H}_{n}$ denotes the full-rank matrix, and $\left(\mathbf{I}_{n}-\mathbf{C}_{n}(L)\right) \mathbf{Y}_{n, t}$ represents the idiosyncratic volatility. Besides, the datadriven method is utilized to identify the number of factors $q$ in $\mathbf{Z}_{n}$.

Through formula (3), the stock market volatility is decomposed into the volatility caused by the common market shock and the idiosyncratic volatility. And, the residuals of the common component $\mathbf{X}_{n}$ can be obtained via the method of Forni et al. [18], while the residuals of the idiosyncratic component $\mathbf{Y}_{n}$ can be obtained via univariate AR fitting. In addition, the shocks driving these two different types of volatility are mathematically orthogonal.

2.2.2. Extreme Risk. Financial risk measurement is the foundation of financial risk supervision, which requires efficient tools. Different from the idiosyncratic risk that reflects the idiosyncratic volatility component, the extreme risk mainly captures the tail risk of the stock market that is caused by an external tail event. The tail events that result in extreme risk are represented by the leptokurtosis and thick tail feature of return distribution as well as the stochastic volatility feature of returns. On this basis, the extreme risks caused by frequent tail events in the stock market can easily induce financial systemic risks. Then, the $\mathrm{VaR}$ and $\mathrm{ES}$ indicators are primarily employed to describe the extreme risk.

$\mathrm{VaR}$ is employed to determine the capital level that financial institutions need to retain in response to financial risks. Let $r_{i t}$ denote the returns of institution $i$ at time $t$, $r_{i t}=100 \times\left(\ln P_{t i}-\ln P_{t, t-1}\right)$. When the confidence level is $1-q$, VaR can be defined as $\operatorname{Pr}\left(r_{i t}<\operatorname{VaR}_{q, t}^{i}\right)=q . \mathrm{VaR}_{q, t}^{i}$ can be understood as the $q$ quantile of asset returns for institution $i$, whose value is generally negative. However, it mainly focuses on the risks of individual institutions and does not reflect the risks when the stability of the whole financial system is in distress.
ES represents the expected loss of individual institutions when the loss of asset returns exceeds $\mathrm{VaR}_{\alpha}$. Regarding the financial system in the crisis state as systemic events, and the threshold $C$ which is used to define the stress event, then the expected loss ES of the financial system at time $t$ can be defined as follows:

$$
\mathrm{ES}_{m, t-1}(C)=E_{t-1}\left(r_{\mathrm{mt}} \mid r_{\mathrm{mt}}<C\right)=\sum_{i=1}^{N} w_{i t} E_{t-1}\left(r_{i t} \mid r_{\mathrm{mt}}<C\right) \text {. }
$$

2.2.3. Systemic Risk. When systemic risks accumulate to a certain degree, the release will cause a large number of institutions to be closed down. Then, it will cause the entire financial system to face systemic crisis. Conditional value at risk ( $\mathrm{CoVaR})$ refers to the risks that the overall financial system face when an institution is in crisis. It can be used to describe the risk spillover relationships between different institutions. It describes the risk degree that the entire financial system ultimately assumes from the information transmission through different channels. Assume that the $C\left(X^{i}\right)$ event occurs in institution $i$ at time $t$, then CoVaR represents the $\mathrm{VaR}$ value of institution $i$ at the confidence level of $1-q$. That is, the conditional risk value of the whole financial system if the loss of institution $i$ is at the level of $\mathrm{VaR}_{q, t}^{i}$. Further, the CoVaR can also be defined as the $q$ quantile of the probability distribution of asset returns:

$$
\operatorname{Pr}\left(r_{j t} \leq \operatorname{CoVaR}_{q, t}^{i \mid C\left(X^{i}\right)} \mid C\left(r_{i}\right)\right)=q,
$$

where $\mathrm{CoVaR}{ }_{q, t}^{i}$ represents the $\mathrm{VaR}$ of the financial system when the institution $i$ is at the $\mathrm{VaR}_{q, t}^{i}$ level, covering the systemic risk spillover effects of institution $i$ on the whole financial system. When examining the systemic risk, the risk contribution degree from individual institution $i$ to the whole financial system can be expressed as the difference between the conditional risk value of the whole financial system when the institution $i$ is in financial distress and the conditional risk value of the system when the institution $i$ is in the median state, which can be expressed in the following formula:

$$
\Delta \operatorname{CoVaR}_{q, t}^{i}=\operatorname{CoVaR}_{q, t}^{C\left(r_{i}\right)}-\operatorname{CoVaR}_{q, t}^{\operatorname{Median}^{i}},
$$

where $\Delta \mathrm{CoVaR}$ indicates the negative external spillover of risks that the individual institution generates on the whole financial system, quantifying the additional risks to the whole financial system when the single institution is under pressure. It captures the marginal contribution of institution $i$ to the total systemic risk, reflecting the marginal risk contribution of the institutions in crisis to the system, with larger absolute values indicating higher degree of systemic risk.

The systemic risk MES represents the marginal contribution of the individual institution to the risk measured by the ES measure, which is the partial derivative of the system ES on the weight of institution $i$. It represents the amount of 
change in the market risk indicator ES caused by the change in the weight of the $i$-th institution in the financial system by one unit. The higher the MES value, the greater the contribution of institution $i$ to systemic risk. According to Scaillet [26], MES can be expressed as the first derivative of ES on weights for the $i$-th asset, which can be expressed as follows:

$$
\text { MES }=\frac{\partial E S_{m, t-1}(C)}{\partial w_{i}}=E_{t-1}\left(r_{i t} \mid r_{\mathrm{mt}}<C\right) .
$$

MES measures all the losses exceeding the $\alpha$ quantile of the loss distribution. The marginal expected shortfall is the expectation of business risk level and profitability of the institution in crisis, which reflects the ability of an institution to resist market risks.

The AR-GARCH-DCC model method is employed to describe the nonlinear risk correlation and clustering property between variables in the stock market and calculates the risk contribution degree of an individual stock to the system. Specifically, the dynamic conditional correlation DCC model is employed to model the dynamic correlation between system returns and individual institution returns primarily. Then, we use the AR-GARCH $(1,1)$ framework to model the volatility and get the conditional volatility and standard residuals of the system and the individual institutions, respectively. The parameter estimation uses the quasimaximum likelihood estimation method to obtain a consistent, asymptotic estimator. Secondly, according to the independent and identical distribution properties of the innovation term of the volatility process, the nonparametric kernel estimation of the tail expectations is performed. Finally, the systemic risk is calculated according to the abovementioned CoVaR and MES risk measurement formulas.

2.3. Model Specification. Using the institutional investors' network topology structure features to characterize the information sharing characteristics, we further analyze the relationship between the information sharing of institutional investors network and different levels of risks. The corresponding risks include idiosyncratic risks, stock market extreme risks, and financial systemic risk. The model can be specified as follows:

$$
\text { risk }_{i t}=\beta_{0}+\beta_{1} \text { density }_{i t}+\beta_{2} \text { degree }_{i t}+\gamma \text { control }_{i t}+\varepsilon_{i t} .
$$

In order to control other factors that affect stock price risk, the following two types of control variables are introduced into the model: (1) valuation variables, including the standard deviation of stock returns (vari), company size (lncapi), ratio of returns to market value (retcap), asset-liability ratio (asslia), price earnings ratio (pe), and the shareholding ratio of major shareholders (holder); (2) the herd effect control variables, including the individual stock turnover (turnover), the price momentum (momen), and the sentiment indicator (willing). The specific definitions and computation methods of the variables are shown in Table 1.

\section{Empirical Results}

3.1. Institutional Investor Information Network. This paper uses the Chinese mutual security investment fund and the listed company stocks as samples. The sample data cover the period from the first quarter of 2007 to the second quarter of 2019, and the data come from the Wind database in China. We select the mutual funds that hold common stocks with large position for the type of ordinary stock funds, hybrid funds with partial stocks, and the balanced hybrid funds during the sample period. Especially, the top holding stocks refer to the stocks being the top ten stocks with the largest positions announced in the quarterly report of the fund, and the market capitalization of these stocks accounts for more than $5 \%$ of the market capitalization of the fund. According to the statistics, the quarterly average of the proportion of the funds with large position stocks in all funds is $41.4 \%$, which indicates that the fund information network has important impacts on the stock volatility. Additionally, it has been found that the size of the fund information network is constantly increasing.

Primarily, based on the 2019 semiannual report data, the overview of the China mutual fund network is pictured, as shown in Figure 1. In Figure 1, the average path length of the network is 1.7049 and the clustering coefficient is 0.7455 , indicating that the Chinese institutional investor network displays small-world features, which reflects rapid speed of information diffusion. In order to more clearly show the stock connection relationship in the fund information network, we take the China Inner Mongolia Yili Industrial Group (Yili) as an example, and the stock network built around Yili shares is shown in Figure 2. In Figure 2, Yili's shares are held by five mutual funds, and the code of these five funds are, respectively, 006429.OF, 004868.OF, 162107.OF, 001186.OF, and 090016.OF, and all these five funds have their own fund information network. Yili's stock network is the collection of the five funds holding its shares and their respective fund information networks.

3.2. Stock Market Extreme Risk and Financial Systemic Risk. Figure 3 shows the daily level of extreme risk measured by the VaR method using individual Chinese stock market data. Systemic events are defined as situations where the market returns exceed 5\% risk threshold level. Judging from the market average value, the degree of extreme risk in the Chinese financial market is low, indicating that the extreme risk in China is generally controllable. In addition to the sharp increase in extreme risks in the Chinese stock market during the international financial crisis in 2008 and the Chinese stock market disaster in 2015, the degree of extreme risks in the Chinese stock market rose again in 2018. This is mainly due to the impact of credit events in China such as the Internet finance defaults, bond defaults, and the escalation of Sino-US trade frictions in 2018, which have increased the degree of systemic risk.

Figure 4 shows the daily level of financial systemic risk in China. Different from the extreme risk of the stock market measured by VaR, the systemic risks measured by $\Delta \mathrm{CoVaR}$ 
TABLE 1: Control variable name and meaning.

\begin{tabular}{|c|c|}
\hline $\begin{array}{l}\text { Control } \\
\text { variable }\end{array}$ & Meaning and computation method \\
\hline Asslia & Asset-liability ratio, total liabilities divided by total assets \\
\hline Holder & $\begin{array}{c}\text { Shareholding ratio of major shareholders, the sum of the shareholding ratios of the top five shareholders in the listed } \\
\text { companies }\end{array}$ \\
\hline $\mathrm{Pe}$ & Price earning ratio, stock price divided by earnings per share \\
\hline Lncapi & Company size, natural logarithm of market capitalization \\
\hline Retcap & Ratio of returns to market value \\
\hline Turnover & Individual stock turnover, ratio of trading volume to the total number of shares issued \\
\hline Vari & Standard deviation of returns, standard deviation of stocks relative to benchmark returns in the fund network \\
\hline Momen & $\begin{array}{c}\text { Price momentum, an indicator analyzing the trend of the stock price based on the variations of the speed of the stock price } \\
\text { changes }\end{array}$ \\
\hline Willing & Sentiment indicator, popular willingness \\
\hline
\end{tabular}

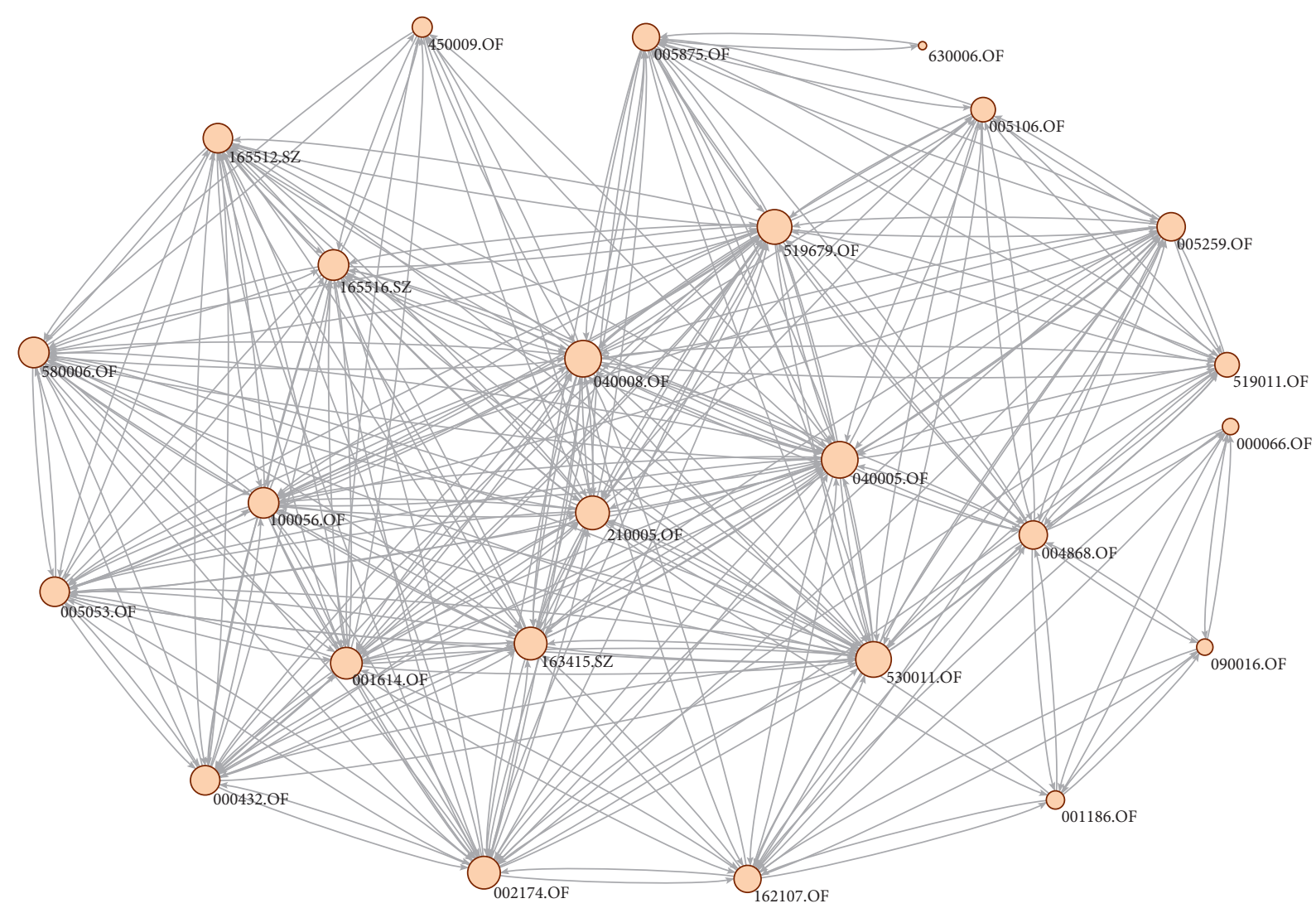

Figure 1: Mutual fund network based on the 2019 semiannual report in China.

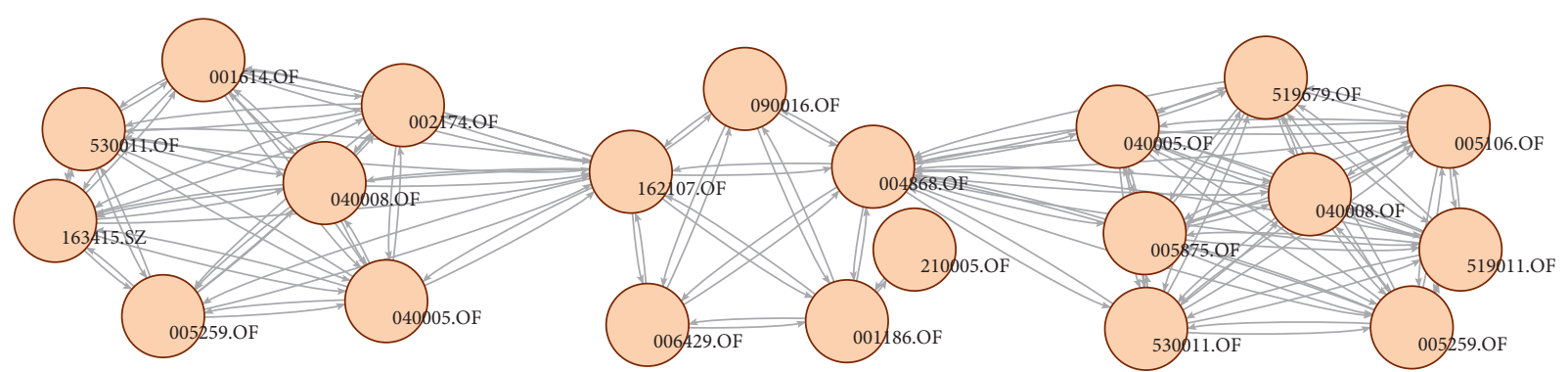

FIGURE 2: Stock network centered on Yili shares. 


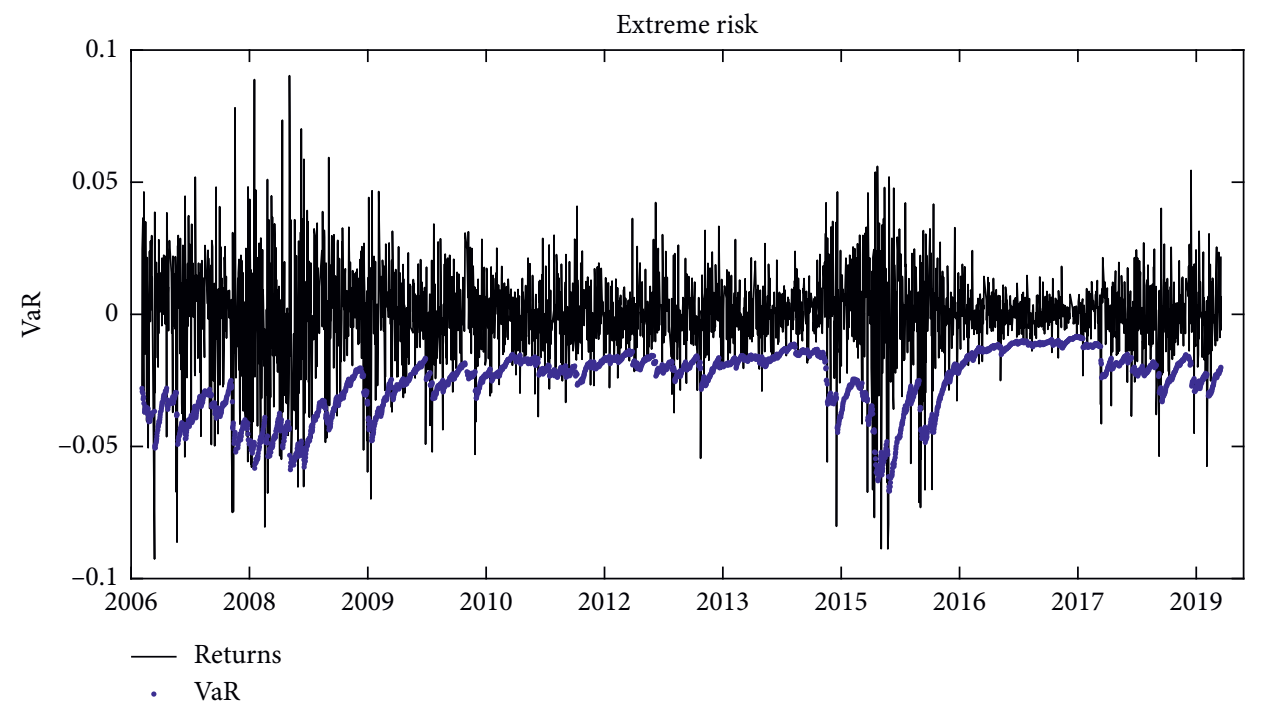

Figure 3: Stock market extreme risks in China.

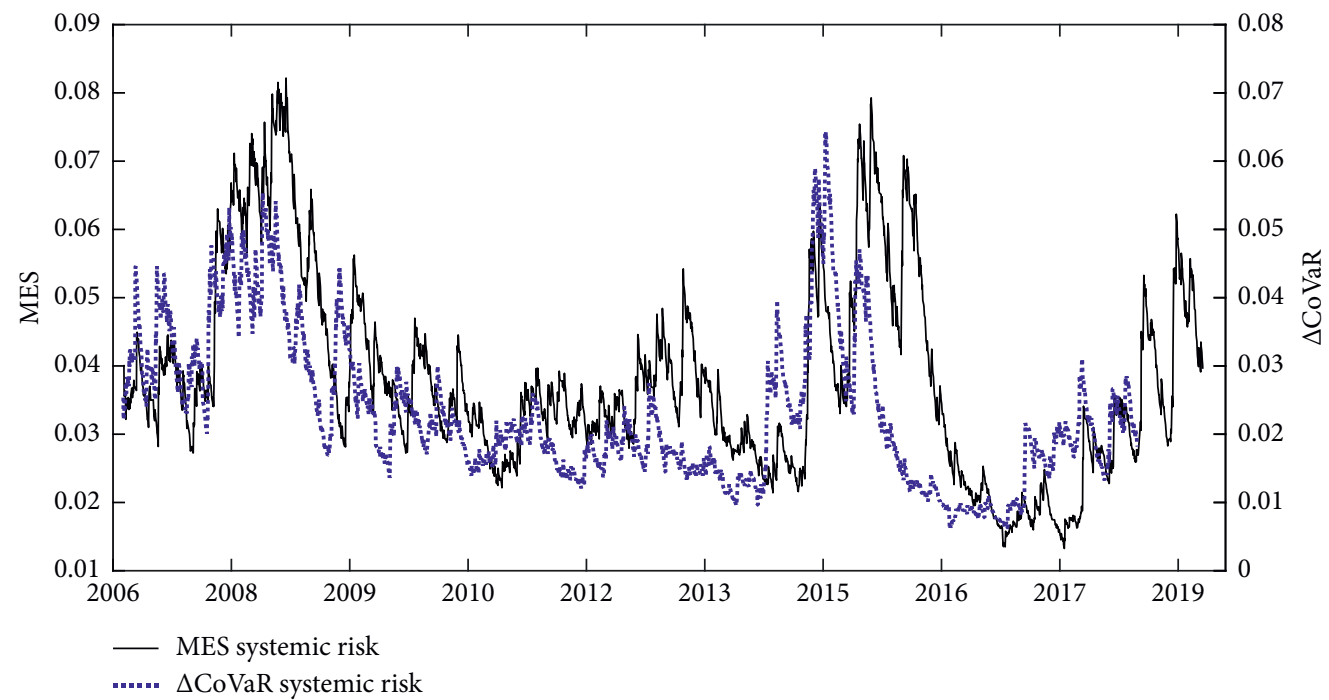

FIgURE 4: Financial systemic risk in China.

and MES not only identify the risk surge caused by the subprime crisis in 2008, the Chinese stock market disaster event in 2015, and the credit defaults in 2018, but also identify the risk surge caused by the money shortage incident in China in 2013. Moreover, the cyclical characteristics of systemic risk in China are obvious, and the systemic risk indicator values of $\triangle \mathrm{CoVaR}$ and MES change significantly during the financial crisis. In 2013, due to the tighter interbank funding and higher interest rates, financial institutions and the related institutions were affected by the risk of money shortage. At the end of 2014, the systemic risk indicator showed gradual rise, and then the risk indicators reached a peak during the turbulent period with thousands of stocks dropping in 2015 subsequently. In 2018, the comprehensive effects caused by the Internet financial defaults, corporate bond defaults, and the escalation of SinoU.S trade frictions impacted the stock markets, making the systemic risk rise sharply. This phenomenon also makes it necessary and urgent to prevent the cross-sectoral transmission of financial risks, so as to prevent the systemic risk occurring.

3.3. Institutional Investor Information Sharing with Extreme Risks and Systemic Risks. The topology structure of the fund network characterizes the efficiency of information sharing. The larger the degree of the network, the faster the propagation speed of the network information, with the efficiency of information sharing improved. The larger network density means that there are small groups of interests in the network, which will hinder the spread of information and reduce the efficiency of information sharing. According to the previous model specification, we analyze the influence of the centralization and network density of the fund 
TABLE 2: The impact of fund information networks on idiosyncratic risks and extreme risks.

\begin{tabular}{lcccccc}
\hline & Idio & $t$ value & VaR & $t$ value & ES & $t$ value \\
\hline Degree & $0.1053^{* *}$ & $(1.9316)$ & $-0.0012^{*}$ & $(-1.7151)$ & $-0.0011^{* *}$ & $(-2.0967)$ \\
Density & $-1.0104^{*}$ & $(-1.8456)$ & $0.0462^{* * *}$ & $(2.6023)$ & $0.0399^{* *}$ & $(2.4270)$ \\
Asslia & 6.4355 & $(1.4979)$ & $0.0894^{* *}$ & $(1.9548)$ & $0.0999^{* *}$ & $(2.3588)$ \\
Holder & $-0.5845^{* * *}$ & $(-4.5066)$ & 0.0003 & $(0.1748)$ & -0.0007 & $(-0.4429)$ \\
Pe & $-1.8 E-04$ & $(-0.2297)$ & $-7.22 E-05$ & $(-0.9398)$ & $-7.57 E-05$ & $(-1.0635)$ \\
Lncapi & $1.2795^{* *}$ & $(2.4647)$ & $-0.0142^{* * *}$ & $(-2.5991)$ & $-0.0126^{* * *}$ & $(-2.4873)$ \\
Retcap & 0.1062 & $(1.3946)$ & $0.0017^{* *}$ & $(2.1773)$ & $0.0013^{*}$ & $(1.7379)$ \\
Turnover & $-0.0111^{* * *}$ & $(-3.5202)$ & $0.0002^{* * *}$ & $(3.6297)$ & $0.0002^{* * *}$ & $(3.8499)$ \\
Momen & $3.9483^{* * *}$ & $(3.0464)$ & $-0.0337^{* * *}$ & $(-2.4880)$ & $-0.030^{* *}$ & $(-2.3859)$ \\
Willing & -0.1276 & $(-0.7351)$ & -0.0002 & $(-0.0654)$ & $-8.19 E-04$ & $(-0.0518)$ \\
Vari & & & $0.0269^{* * *}$ & $(3.7005)$ & $0.0029^{*}$ & $(1.9466)$ \\
Adjusted $R^{2}$ & & 0.36 & 0.61 & 0.69 & & \\
\hline
\end{tabular}

***, ${ }^{* *}$, and ${ }^{*}$ indicate statistical significance at $1 \%, 5 \%$, and $10 \%$ level, respectively.

TABle 3: The impact of fund information network on systemic risk.

\begin{tabular}{lcccc}
\hline & CoVaR & $t$ value & MES & $t$ value \\
\hline Degree & $-0.0011^{* *}$ & $(-2.2873)$ & $-0.0012^{*}$ & $(-1.9013)$ \\
Density & $0.0385^{* *}$ & $(2.3972)$ & $0.0579^{* * *}$ & $(2.5451)$ \\
Asslia & $0.0962^{* *}$ & $(2.3279)$ & $0.1139^{*}$ & $(1.9391)$ \\
Holder & -0.0005 & $(-0.3875)$ & 0.0003 & $(0.1695)$ \\
Pe & $-7.5 E-05$ & $(-1.0802)$ & $-9.71 \mathrm{E}-05$ & $(-0.9854)$ \\
Lncapi & $-0.0129^{* *}$ & $(-2.6001)$ & $-0.0189^{* * *}$ & $(-2.6887)$ \\
Retcap & $0.0011^{*}$ & $(1.7113)$ & $0.0021^{* *}$ & $(2.1298)$ \\
Turnover & $0.0002^{* * *}$ & $(3.5983)$ & $0.0002^{* * *}$ & $(3.4348)$ \\
Momen & $-0.0275^{* *}$ & $(-2.2469)$ & $-0.0416^{* *}$ & $(-2.3984)$ \\
Willing & 0.0005 & $(0.3683)$ & 0.0005 & $(0.2371)$ \\
Vari & $0.0025^{*}$ & $(1.6923)$ & 0.0022 & $(1.0626)$ \\
Adjusted $R^{2}$ & & 0.65 & 0.59 & \\
\hline
\end{tabular}

${ }^{* * *},{ }^{* *}$, and ${ }^{*}$ indicate statistical significance at $1 \%, 5 \%$, and $10 \%$ level, respectively.

information network on the idiosyncratic risk of stock volatility and the extreme risk in the stock market. Seen from the results shown in Table 2, it can be seen that the centralization degree of the fund information network has positive correlation with the idiosyncratic risk of individual volatility after controlling other related factors. However, the network density and the idiosyncratic volatility show negative correlation. In other words, institutional investor information sharing has exacerbated the idiosyncratic volatility of individual stock prices. This is mainly because institutional investors learn from each other, which results in similar investment decisions. Information sharing improves the consistency of the trading operation of fund managers and forms herd effects. The herd effects of institutional investors prevent information from being comprehensively incorporated into the stock price in a timely manner, which increases the stock volatility in the short term. As far as individual stock volatility is concerned, it is necessary to reduce the risk of stock market crashes caused by institutional investors imitating each other.

Seen from the consequences of extreme risks, the centralization degree of the fund information network displays negative correlation with the extreme risks of the stock market measured by $\mathrm{VaR}$ and ES methods after controlling other related factors. And, the network density and the extreme risks of the stock market measured by VaR and ES methods also display significant positive correlation. It indicates that information sharing between institutional investors can reduce extreme risks in the stock market. Besides, the effects of fund information networks on idiosyncratic risk and extreme risk are different. Specifically, the effects on individual stock volatility can be realized in the short period, while the effects on extreme risks need relative longer time to be fully transmitted to the market.

Furthermore, we analyze the influences of centralization and network density of the fund information network on systemic risks, with the results shown in Table 3. Judging from the consequences of systemic risk, the degree of centralization of the fund information network displays negative correlation with the systemic risk measured by $\mathrm{CoVaR}$ and MES indicators. However, the network density displays significant positive correlation with the systemic risk. It indicates that information sharing among institutional investors can reduce the systemic risks. This is mainly because the information sharing among institutional investors improves the comprehensiveness and accuracy of market information transmission, so that it can improve the market pricing efficiency of stocks. Through reducing the extreme risks in the stock market, it further reduces the degree of financial systemic risk. It implies that improving the quality of information disclosures of institutional investor helps reduce extreme risk and systemic risk. 


\section{Conclusion}

This paper assumes that there exists private information sharing among funds that hold common stocks with large position. Then, we build the institutional investor information network using the common holding stocks of mutual funds as links. And, the impacts of information sharing efficiency represented by the network topology structure on the extreme risk of stock market and financial systemic risk are investigated. Based on the empirical analysis of China mutual fund and stock market data from 2007 to 2019, we reveal the inherent formation mechanism of fund herd behaviors. The studies find that the Chinese institutional investor network exhibits small-world characteristics, which reflects fast speed of information diffusion. After controlling other related factors, it can be found that from the idiosyncratic risk of individual volatility, institutional investor information sharing has increased the idiosyncratic risk. However, from the perspective of the effects on stock market extreme risk, there exists negative relationship between information sharing of the institutional investor network and the stock market extreme risk. That is, information sharing among institutional investors reduces extreme risk in the stock market. In addition, there exists a negative relationship between institutional investor information sharing and systemic risk, meaning that information sharing among institutional investors reduces financial systemic risk.

It indicates that in order to prevent the transmission of systemic risk, it is necessary to pay attention to the role of information flow of the fund manager in the social networks. Institutional investor information sharing reduces the probability of black swan incidents by improving the comprehensiveness of market information transmission and the market pricing efficiency of stocks. The conclusions of the study provide reference for regulators to stabilize the market and to prevent the manipulation of stock prices caused by the herd effects of investors. As far as individual stock volatility is concerned, it is necessary to reduce the risk of stock market crashes caused by institutional investors imitating each other. Concerning the extreme risk and systemic risk, improving the quality of information disclosures of institutional investor helps reduce these risks. The obtained conclusions are also instructive for regulators and investors in other financial markets. The use of the fund information network contributes to identifying important institutional investors so as to conduct targeted supervision and prevent manipulation of stock prices.

\section{Data Availability}

The Wind database data (Excel type) used to support the findings of this study are available from the corresponding author upon request.

\section{Conflicts of Interest}

The authors declare that they have no conflicts of interest.

\section{Acknowledgments}

The authors would like to acknowledge the financial support from the National Natural Science Foundation of China (nos. 71901130, 71532009, and 71790594), Shandong Social Science Planning Project (no. 19CJRJ21), and China Postdoctoral Science Foundation (2018M641653).

\section{References}

[1] W. Li, G. Rhee, and S. S. Wang, "Differences in herding: individual vs. institutional investors," Pacific-Basin Finance Journal, vol. 45, pp. 174-185, 2017.

[2] N. C. Brown, K. D. Wei, and R. Wermers, "Analyst recommendations, mutual fund herding, and overreaction in stock prices," Management Science, vol. 60, no. 1, pp. 1-20, 2013.

[3] P. Irvine, M. Lipson, and A. Puckett, “Tipping," Review of Financial Studies, vol. 20, no. 3, pp. 741-768, 2007.

[4] V. K. Pool, N. Stoffman, and S. E. Yonker, "No place like home: familiarity in mutual fund manager portfolio choice," Review of Financial Studies, vol. 25, no. 8, pp. 2563-2599, 2012.

[5] V. K. Pool, N. Stoffman, and S. E. Yonker, "The people in your neighborhood: social interactions and mutual fund portfolios," The Journal of Finance, vol. 70, no. 6, pp. 2679-2732, 2015.

[6] G. Cici, S. Jaspersen, and A. Kempf, "Speed of information diffusion within fund families," Review of Asset Pricing Studies, vol. 7, no. 1, pp. 144-170, 2017.

[7] A. Pareek, "Information networks: implications for mutual fund trading behavior and stock returns," in Proceedings of the Atlanta Meetings Paper, Atlanta, GA, USA, January 2012.

[8] J.-B. Kim, Y. Li, and L. Zhang, "Corporate tax avoidance and stock price crash risk: firm-level analysis," Journal of Financial Economics, vol. 100, no. 3, pp. 639-662, 2011.

[9] H. N. Ozsoylev, J. Walden, M. D. Yavuz, and R. Bildik, "Investor networks in the stock market," Review of Financial Studies, vol. 27, no. 5, pp. 1323-1366, 2014.

[10] J. Blocher, "Network externalities in mutual funds," Journal of Financial Markets, vol. 30, pp. 1-26, 2016.

[11] M. Billio, M. Getmansky, A. W. Lo, and L. Pelizzon, "Econometric measures of connectedness and systemic risk in the finance and insurance sectors," Journal of Financial Economics, vol. 104, no. 3, pp. 535-559, 2012.

[12] Z. Yang and Y. Zhou, "Quantitative easing and volatility spillovers across countries and asset classes," Management Science, vol. 63, no. 2, pp. 333-354, 2017.

[13] P. Colla and A. Mele, "Information linkages and correlated trading," Review of Financial Studies, vol. 23, no. 1, pp. 203-246, 2010.

[14] S. S. Crawford, W. R. Gray, and A. E. Kern, "Why do fund managers identify and share profitable ideas?" Journal of Financial and Quantitative Analysis, vol. 52, no. 5, pp. 1903-1926, 2017.

[15] A. Krause and S. Giansante, "Interbank lending and the spread of bank failures: a network model of systemic risk," Journal of Economic Behavior \& Organization, vol. 83, no. 3, pp. 583-608, 2012.

[16] A. W. Butler and U. G. Gurun, "Educational networks, mutual fund voting patterns, and CEO compensation," Review of Financial Studies, vol. 25, no. 8, pp. 2533-2562, 2012.

[17] M. Barigozzi and M. Hallin, "A network analysis of the volatility of high dimensional financial series," Journal of the 
Royal Statistical Society: Series C (Applied Statistics), vol. 66, no. 3, pp. 581-605, 2017.

[18] M. Forni, M. Hallin, M. Lippi, and P. Zaffaroni, "Dynamic factor models with infinite-dimensional factor spaces: onesided representations," Journal of Econometrics, vol. 185, no. 2, pp. 359-371, 2015.

[19] T. Adrian and M. K. Brunnermeier, "CoVaR," American Economic Review, vol. 106, no. 7, pp. 1705-1741, 2016.

[20] M. Rodríguez-Moreno and J. I. Peña, "Systemic risk measures: the simpler the better?" Journal of Banking \& Finance, vol. 37, no. 6, pp. 1817-1831, 2013.

[21] V. V. Acharya, L. H. Pedersen, T. Philippon, and M. Richardson, "Measuring systemic risk," Review of Financial Studies, vol. 30, no. 1, pp. 2-47, 2017.

[22] E. N. Karimalis and N. K. Nomikos, "Measuring systemic risk in the European banking sector: a copula CoVaR approach," The European Journal of Finance, vol. 24, no. 11, pp. 944-975, 2018.

[23] J. L. Callen and X. Fang, "Institutional investor stability and crash risk: monitoring versus short-termism?" Journal of Banking \& Finance, vol. 37, no. 8, pp. 3047-3063, 2013.

[24] H. An and T. Zhang, "Stock price synchronicity, crash risk, and institutional investors," Journal of Corporate Finance, vol. 21, pp. 1-15, 2013.

[25] J. Fan, Y. Liao, and X. Shi, "Risks of large portfolios," Journal of Econometrics, vol. 186, no. 2, pp. 367-387, 2013.

[26] O. Scaillet, "Nonparametric estimation and sensitivity analysis of expected shortfall," Mathematical Finance, vol. 14, no. 1, pp. 115-129, 2004. 